With 1 plate

Printed in Great Britain

\title{
Morphological Response of Trichophyton mentagrophytes to Methionine
}

\author{
By DEANA T. KLEIN \\ Department of Microbiology and Immunology, Albert Einstein College of Medicine. \\ New York 61, New York, U.S.A.
}

(Received 31 July 1962)

\begin{abstract}
SUMMARY
Granular cultures of Trichophyton mentagrophytes changed their growth habit when grown on a medium containing, as the source of nitrogen, the $19 \mathrm{~L}$-amino acids found in hydrolysed casein, a response not seen when methionine was omitted. In contrast, pleomorphic cultures of T. mentagrophytes grown on amino acid medium were not modified. The methionine effect has been used successfully to differentiate between normal granular cultures and mutant pleomorphic cultures. Also, isolates characterized as atypical pleomorphs could be classified as metabolically granular or pleomorphic.
\end{abstract}

\section{INTRODUCTION}

Sabouraud (1910) described a striking morphological alteration in old cultures of dermatophyte fungi where tufts of downy or woolly white mycelium grew on the surface of the parent granular culture. Isolated tufts remained fluffy and did not revert to the parental type. Sabouraud termed these alterations pleomorphic and considered that they represented 'fixed mutations'. He observed that all studied species of Trichophyton formed pleomorphs which lost the ability to form macroconidia and chlamydospores, although all continued to produce microconidia. A working definition of a pleomorphic mutant based on Sabouraud's original and still valid observations must include a description of the surface growth as fluffy or downy, the loss of ability to form pigment, and sporulation only as microconidia. Granular cultures of Trichophyton mentagrophytes (Robin) Blanchard differ markedly from pleomorphic cultures in that the surface growth is appressed and 'grainy' in appearance, both surface and reverse sides of the colony are pigmented, and macroand microconidia as well as chlamydospores are formed. Although Sabouraud reported that all pleomorphic cultures looked the same, Robbins \& McVeigh (1949) described a series of pleomorphic isolates from a granular culture of $T$. mentagrophytes which varied in their modes of surface growth. Thus, a morphological description alone may not be sufficient to describe pleomorphism when there are gradations or degrees of alteration. As part of a project to elucidate the metabolic and genetic basis for the observed growth patterns in pleomorphism, the responses of granular and pleomorphic cultures of $T$. mentagrophytes to a variety of metabolic and physical stresses are being examined. The work to be reported describes one such metabolic stress, i.e. a culture medium containing methionine which successfully distinguishes between typical granular and typical pleomorphic cultures. Based on the type of morphological response to methionine, isolates otherwise intermediate in appearance can be classified as metabolically granular or pleomorphic. 


\section{METHODS}

Organisms. Cultures of Trichophyton mentagrophytes were obtained from Dr W. J. Robbins (New York Botanical Garden) and Dr L. Ajello (Communicable Disease Centre, Atlanta, Georgia). Cultures of several dermatophyte fungi were obtained from Dr E. O'Hern (Downstate Medical Centre, Brooklyn, New York) and the Department of Microbiology and Immunology (Albert Einstein College of Medicine).

Culture media. All media used were identical except for the nitrogen source. The basal medium contained (g. or ml./l.): $\mathrm{MgSO}_{4} .7 \mathrm{H}_{2} \mathrm{O}, 0.5 ; \mathrm{KH}_{2} \mathrm{PO}_{4}, \mathbf{1 . 5} ; \mathrm{K}_{2} \mathrm{HPO}_{4}$, $0 \cdot 15$; trace element solution, 0.5 ; thiamine stock $(1 \mathrm{mg} . / \mathrm{ml}$.), 10 ; glucose, 20 ; agar, 15. Stock medium contained Difco Neopeptone at $0 \cdot 2 \%(\mathrm{w} / \mathrm{v})$. Experimental media contained one of the following nitrogen sources: (1) Vitamin-free acid hydrolysed casein (General Biochemicals Co. or Nutritional Biochemicals Corp.), 20 ml./l. to give a final concentration of $2 \mathrm{mg}$. casein $/ \mathrm{ml}$.; tryptophan (40 $\mu \mathrm{g}$. $/ \mathrm{ml}$.) was added to casein medium since acid hydrolysis destroys the tryptophan normally present; (2) $19 \mathrm{~L}$-amino acids (California Corporation for Biochemical Research) each at the same concentration as found in acid hydrolysed casein (including tryptophan) to give a final concentration of $\mathbf{1 \cdot 7 6} \mathrm{mg}$. amino acids $/ \mathrm{ml}$. Analysis of the hydrolysed casein (personal communication, Dr W. J. Robbins) used here differs somewhat from that of casein published (McMeekin, 1954); hence, it was felt worth while to give the analysis here. Twenty $\mathrm{ml}$. hydrolysed casein contained mM.: alanine, 0.43 ; arginine, 0.44 ; aspartic acid, 0.62 ; cystine, 0.025 ; glutamic acid, 2.97; glycine, 0.13 ; histidine, 0.32 ; hydroxyproline, 0.03 ; iso-leucine, 0.75 ; leucine, 0.96 ; lysine, 0.74 ; methionine, 0.46 ; phenylalanine, 0.47 ; proline, 1.56 ; serine, 0.095; threonine, 0.47 ; tryptophan, 0.22 ; tryosine, 0.72 ; valine, 1.35 . The $19 \mathrm{~L}$-amino acid medium was also used when various analogues and homologues of methionine (Nutritional Biochemicals Corp.) were tested. All media were adjusted to $\mathrm{pH} \mathbf{5} \cdot \mathbf{7}$.

Conditions of growth. Stock cultures were grown in test tubes on Neopeptone medium and stored at $5^{\circ}$. Cultures used as a source of inoculum were grown in Petri dishes on Neopeptone medium at $26^{\circ}$. Inocula for all experiments were disks of agar cut from the advancing edge of mycelial growth with a sterile cork borer (4 $\mathrm{mm}$. diameter) and placed, one disk/plate, at the centre of the experimental agar medium. All cultures were incubated at $26^{\circ}$ for 2 weeks at which time observations were made.

\section{RESULTS}

Macroscopic appearance. When grown on amino acid medium, Trichophyton mentagrophytes (M12-4, NYBG) had an uneven irregular advancing hyphal edge (Pl. 1, fig. 1) contrasting with the smooth edge on hydrolysed casein medium; but a typical pleomorphic culture (T16-12, NYBG) did not change on the 19 L-amino acid medium (Pl. 1, figs. 3, 4). When methionine was omitted from the amino acid medium there was no morphological response by the granular culture (Pl. 1, fig. 2); when each of the other amino acids was omitted singly, with methionine present, there was still a positive response. When subcultured from amino acid medium to Neopeptone or casein medium, the growth pattern of the granular culture immediately returned to normal. On amino acid medium, the rates of growth of the granular and pleomorphic cultures were slightly lower with than without methionine. 
Microscopic appearance. Growth of the granular culture, M12-4, on amino acid medium increased the number of lateral hyphae which formed along the length of most of the main hyphae ( $\mathrm{Pl} .1$, fig. 5). The number of lateral hyphae did not increase when the fungus was grown on amino acid medium without methionine or on casein medium (Pl. 1, fig. 6).

Response of different species to methionine. Many granular and pleomorphic cultures were screened to determine their morphological response to amino acid medium. The New York Botanical Garden collection of granular and various pleomorphic cultures of Trichophyton mentagrophytes, when tested on amino acid medium (Table 1), could be grouped as follows in terms of response to methionine: (1) granular surface, pigmented reverse, positive morphological response; (2) typical fluffy pleomorph surface, white reverse, no response. A few atypical pleomorphs responded to methionine; they differed in having surface mycelium that was not fluffy, but was fuzzy or appressed with some pigment on the reverse.

Table 1. Response of several species of dermatophyte fungi to methionine in an amino acid medium

\begin{tabular}{|c|c|c|c|c|}
\hline \multirow[b]{2}{*}{ Organism } & \multicolumn{3}{|c|}{$\begin{array}{c}\text { Appearance on Neopeptone } \\
\text { medium }\end{array}$} & \multirow{2}{*}{$\begin{array}{l}\text { Morphological } \\
\text { response } \\
\text { to } \\
\text { methionine. } \\
\text { No. positive/ } \\
\text { no. tested }\end{array}$} \\
\hline & Source & Surface & $\begin{array}{l}\text { Pigmenta- } \\
\text { tion on } \\
\text { reverse } \\
\text { side of } \\
\text { colony }\end{array}$ & \\
\hline Trichophyton mentagrophytes & NYBG* & Granular & + & $14 / 14$ \\
\hline T. mentagrophytes & NYBG & Fluffy & - & $0 / 10$ \\
\hline T. mentagrophytes & NYBG & Fluffy & + & $\mathbf{0} / \mathbf{3}$ \\
\hline T. mentagrophytes & NYBG & Appressed & - & $\mathbf{0} / \mathbf{1}$ \\
\hline T. mentagrophytes & NYBG & Appressed & + & $4 / 12$ \\
\hline T. mentagrophytes & $\mathrm{CDC} \uparrow$ & Granular & + & $7 / 8$ \\
\hline T. mentagrophytes & CDC & Fluffy & - & $0 / 2$ \\
\hline T. mentagrophytes & AECM $\ddagger$ & Granular & + & $1 / 1$ \\
\hline$T . r u b r u m$ & AECM & Granular & + & $1 / 1$ \\
\hline Microsporum audouinii & AECM & Granular & + & $0 / 1$ \\
\hline M. canis & AECM & Granular & + & $0 / 1$ \\
\hline M. gypseum & AECM & Granular & + & $0 / 1$ \\
\hline Epidermophyton floccosum & Brooklyn§ & Granular & + & $0 / 1$ \\
\hline
\end{tabular}

* New York Botanical Garden. † Communicable Disease Centre. $\ddagger$ Albert Einstein College. of Medicine. § Downstate Medical Centre.

Granular cultures of Trichophyton mentagrophytes obtained from other collections also responded to methionine. Pleomorphs, isolated from two of the Communicable Disease Centre cultures of $T$. mentagrophytes which responded to methionine, no longer showed the morphological modification of growth (Table 1). Species of Microsporum and Epidermophyton were tested on amino acid medium, but gave no positive response to methionine.

In addition to data on the response to methionine by the large number of stock Trichophyton cultures (Table 1), further tests were made on 112 new isolates derived from pleomorphic patches which formed on the surface of a granular culture of Trichophyton mentagrophytes (M12-4). Again, typical pleomorphs did 
not respond to methionine, but a few, classified as atypical, did show a positive response, although most atypical pleomorphs did not respond.

Mechanism of action of methionine. Granular cultures responded whether methionine was added to the $19 \mathrm{~L}$-amino acid medium before or after autoclaving, indicating the inducing agent was methionine and not a breakdown product. There was no effect when methionine $(0.46 \mathrm{~mm})$ was the sole source of nitrogen and, interestingly, there was very little methionine effect when methionine at $0.46 \mathrm{~mm}$ was added to casein medium. A positive morphological response to amino acid medium containing methionine depended neither on the type nor concentration of the sugar used as a source of carbon.

Table 2. Effect of adding various compounds to an amino acid medium containing methionine on the morphological response of a granular culture of Trichophyton mentagrophytes (M 12-4)

\begin{tabular}{|c|c|c|c|}
\hline \multirow[b]{2}{*}{ Compound added } & \multirow{2}{*}{$\begin{array}{c}\text { Concentration } \\
(\mathrm{mM})\end{array}$} & \multicolumn{2}{|c|}{ methionine effect } \\
\hline & & Reverse & Increase \\
\hline Thiourea & $\begin{array}{l}0 \cdot 11 \\
0 \cdot 23 \\
0 \cdot 46 \\
1 \cdot 4\end{array}$ & $\begin{array}{l}\text { No } \\
\text { Partial } \\
\text { Complete } \\
\text { Complete }\end{array}$ & $\begin{array}{l}\text { No } \\
\text { No } \\
\text { No } \\
\text { No }\end{array}$ \\
\hline S-Methyl-L-cysteine & $\begin{array}{l}0 \cdot 46 \\
1 \cdot 4\end{array}$ & $\begin{array}{l}\text { No } \\
\text { Partial }\end{array}$ & $\begin{array}{l}\text { No } \\
\text { No }\end{array}$ \\
\hline DL-Methionine sulfone & $\begin{array}{l}0 \cdot 46 \\
1 \cdot 4\end{array}$ & $\begin{array}{l}\text { No } \\
\text { Complete }\end{array}$ & $\begin{array}{l}\text { No } \\
\text { No }\end{array}$ \\
\hline DL-Methionine sulfoxide & $\begin{array}{l}0 \cdot 46 \\
1 \cdot 4 \\
2 \cdot 3\end{array}$ & $\begin{array}{l}\text { No } \\
\text { Partial } \\
\text { Complete }\end{array}$ & $\begin{array}{l}\text { No } \\
\text { No } \\
\text { No }\end{array}$ \\
\hline Methionine, hydroxy analogue & $\begin{array}{l}0 \cdot 46 \\
1 \cdot 4\end{array}$ & $\begin{array}{l}\text { No } \\
\text { Partial }\end{array}$ & $\begin{array}{l}\text { No } \\
\text { No }\end{array}$ \\
\hline
\end{tabular}

Intensity of the methionine effect depended on its concentration in the $19 \mathrm{~L}$ amino acid medium; at $\mathbf{0 . 2 3} \mathbf{m m}$, the response was diminished as compared with that with $0.46 \mathrm{~mm}$; when methionine was increased two- or threefold, the morphological response was greatly intensified. From a series of experiments it was concluded that a particular balance as well as concentration of amino acids, including methionine, was required to cause the methionine effect. There was a morphological response to methionine when the formula for hydrolysed casein (Dr W. J. Robbins, personal communication) or for casein (McMeekin, 1954) was used. When all $19 \mathrm{~L}$-amino acids were supplied at $1.0 \mathrm{mM}$ each, the methionine effect was diminished.

Several homologues and analogues of methionine were tested to determine whether any could mimic the methionine effect. Only D-methionine could replace the L-form but the effective concentration was three times that of the L-form. Among reducing compounds such as ascorbic acid, L-cysteine and thiourea, only the latter (Table 2) modified the methionine effect. S-methyl-L-cysteine (the lower homologue of methionine), DL-methionine sulphone, DL-methionine sulphoxide and methionine hydroxy analogue ( $\alpha$-hydroxy- $\gamma$-methylmercaptobutyric acid) annulled the methionine effect (Table 2 ). Incubation at $36^{\circ}$ instead of $26^{\circ}$, or raising 
the $\mathrm{pH}$ above $6 \cdot 0$ also annulled the methionine effect. Ethionine, homocystine, methylmethionine sulphonium chloride, methylmethionine sulphonium iodide, L-canavanine, 2,4-dinitrophenol, tryptazan, sodium malonate, sodium fluoride, sodium arsenite, chloramphenicol, or betaine $\mathrm{HCl}$ did not modify the methionine effect.

\section{DISCUSSION}

The pattern of growth response of Trichophyton mentagrophytes to the 19 L-amino acid medium has been used successfully as a scoring procedure in classifying morphologically typical or atypical pleomorphic isolates as being metabolically either granular or pleomorph. Although the mechanism whereby methionine exerts a morphological effect on granular cultures of $T$. mentagrophytes is yet unknown, this does not detract from its utility in revealing a metabolic difference between the normal granular and the pleomorphic cultures. This may mean that the working definition of pleomorphism in Trichophyton should now include the methionine effect.

Amino acids are known to play a role in cell division in lower organisms. In the fungus $U$ stilago sphaerogena (Spoerl, Saracheck \& Smith, 1957) and the alga Chlorella vulgaris (Shrift, 1960) methionine specifically affected division processes. These effects were associated with one amino acid, while the change in morphology of the granular culture of Trichophyton mentagrophytes resulted from an interaction between methionine and one or more of the amino acids in the medium. Nevertheless, an effect on division processes was part of the morphological response in T. mentagrophytes since the number of lateral hyphae was increased when the fungus was grown on amino acid medium containing methionine.

The term 'paramorphogenic response' was coined by Tatum, Barrett \& Cutter (1949) to describe the environmentally induced qualitative change in growth habit which occurred when Neurospora and Syncephalastrum were grown on media containing such chemicals as L-sorbose or sodium deoxycholate. The effect of methionine on Trichophyton mentagrophytes would seem to fit such a definition; however, the term may not be applicable here since the morphological response seems to be restricted to granular cultures of Trichophyton.

This investigation was supported by Grant E-2876 from the National Institute of Allergy and Infectious Diseases, U.S. Public Health Service. I thank Dr Elsa O'Donnell for taking the photographs of figs. 5 and 6, and Mrs Geraldyne White for her excellent technical assistance.

\section{REFERENCES}

McMeekin, T. L. (1954). Milk proteins. In The Proteins, 2, part A, 1st ed. Ed. by H. Neurath \& K. Bailey. New York: Academic Press.

Robbins, W. J. \& McVeigh, I. (1949). The 'dual phenomenon' and Trichophyton mentagrophytes. Mycologia, 41, 128.

Sabouraud, R. (1910). Les Teignes, p. 598. Paris: Masson et Cie.

Shrift, A. (1960). A role for methionine in division of Chlorella vulgaris. Plant Physiol. $35,510$.

Spoerl, E., Saracheck, A. \& Smith, S. B. (1957). The effect of amino acids upon cell division in Ustilago. Amer. J. Bot. 44, 252.

Tatum, E. L., Barrett, R. W. \& CutTer, Jun., V. M. (1949). Chemical induction of colonial paramorphs in Neurospora and Syncephalastrum. Science, 109, 509. 


\section{EXPLANATION OF PLATE}

Fig. 1. Trichophyton mentagrophytes, granular culture $\mathrm{M12-4}$, on amino acid medium containing methionine; incubation for 17 days at $26^{\circ}$.

Fig. 2. Granular culture $M 12-4$ on amino acid medium without methionine; incubation for 14 days at $26^{\circ}$.

Fig. 3. T. mentagrophytes, pleomorphic culture T 16-12, on amino acid medium containing methionine; incubation for 14 days at $26^{\circ}$.

Fig. 4. Pleomorphic culture T16-12 on amino acid medium without methionine; incubation for 14 days at $26^{\circ}$.

Fig. 5. Granular culture M12-4 on amino acid medium containing methionine.

Fig. 6. Granular culture M12-4 on casein medium. 
Journal of General Microbiology, Vol. 31, No. 1

Plate 1
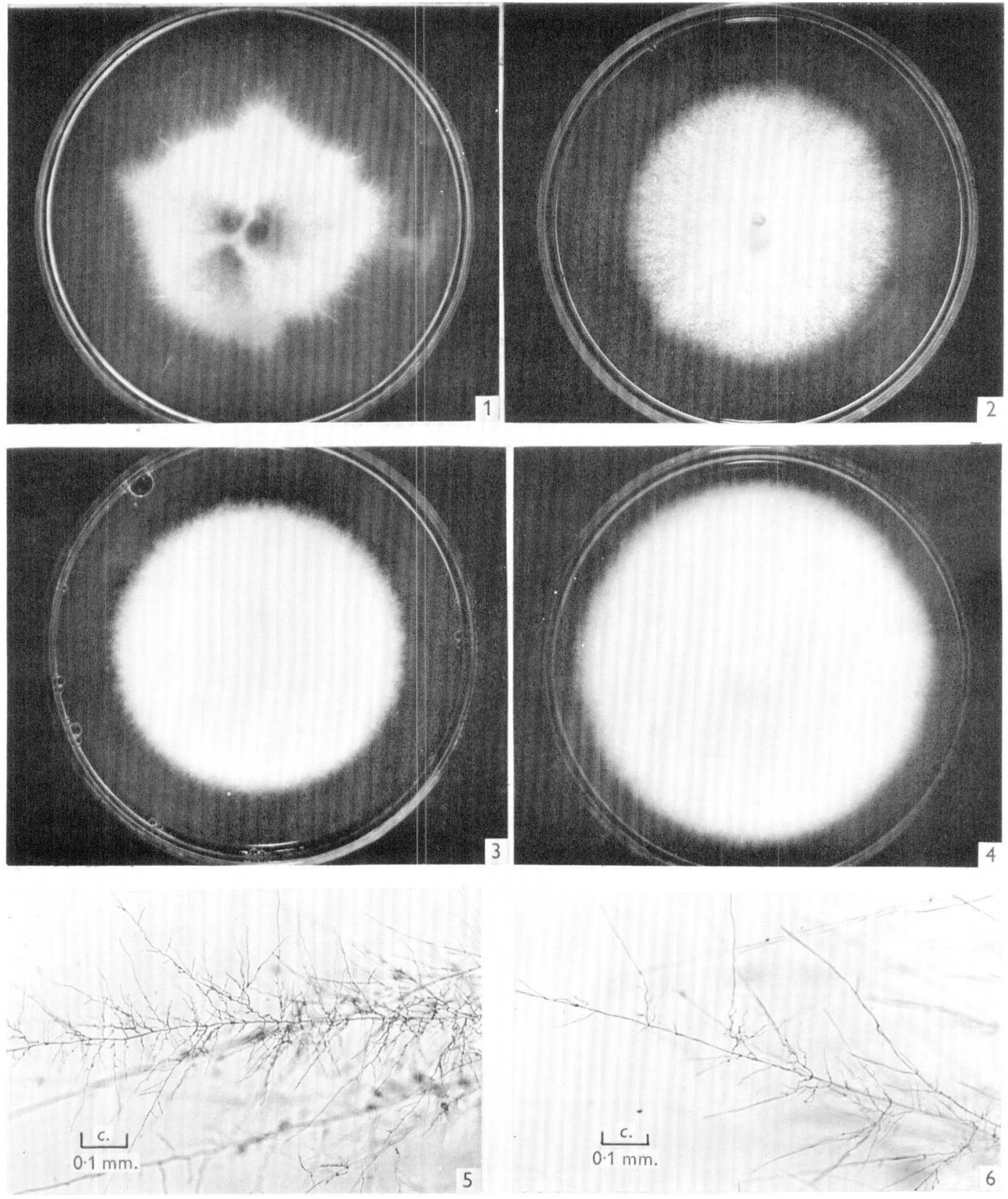

D. T. KLEIN

(Facing p. 96) 